\title{
Analysis of The Solution to The $0.5 \%$ of Global Sulfur Limits of Ships by 2020
}

\author{
Yanhong Zhao ${ }^{1, ~ a, ~ Y a n g ~ X u^{2, b}, \text { Lijiao Zhou }^{3, c}, \text {,Xingmin Zhao }}{ }^{4, d}$, Yaning Wang ${ }^{* 5, e}$ \\ ${ }^{1}$ Petrochemical and Energy Engineering College, Zhejiang Ocean University, Zhoushan , China; \\ ${ }^{2}$ China Petroleum Pipeline Engineering CO.,LTD,Langfang,China; \\ ${ }^{3}$ China Petroleum Pipeline Engineering CO.,LTD,Langfang,China; \\ ${ }^{4}$ China Petroleum Pipeline Engineering CO.,LTD,Langfang,China; \\ ${ }^{*}$ Innovative application research institute,Zhejiang Ocean University, Zhoushan , China; \\ adbsyzyh@126.com, bxyxuyang@cnpc.com, c158475652@qq.com, d315478331@qq.com, \\ ewyn198399@126.com
}

Keywords: $0.5 \%$ global sulfur restriction,Low sulphur fuel oil,SO $\mathrm{S}_{\mathrm{x}}$ Scrubbers,LNG

Abstract. For the international maritime organization (IMO) has decided to implement $0.5 \%$ of global sulfur restrictions by 2020,the paper focuses on three main countermeasures,advice on the relationship between the advantages and disadvantages of the three countermeasures shall be given.It is hoped that the plan selection of future ships to deal with sulfur emission limit will be helpful.

\section{Introduction}

With the rapid development of global economic integration, international trade has become more and more busy.Shipping business is booming.However, with the increase of the number of ships, the discharge of ships has become an important factor affecting the environment.

Marine pollution is quietly becoming the third major source of air pollution after automotive exhausts and industrial enterprise emissions.According to calculations by the Shenzhen institute of environmental science, a medium-size container ship with a sulphur content of $3.5 \%$ of fuel has been traveling for 24 hours with $70 \%$ of its maximum power, the emissions of PM2.5 is equivalent to 210000 heavy trucks ${ }^{[1]}$.The excessive discharge of sulfide in ships has attracted the attention of many countries and organizations, a series of new regulations on the sulfur content in Marine fuel have been put into practice.The ship's use of low-sulphur fuel is imperative.

\section{IMO requirements}

On October 27th local time in London, IMO decided that $0.5 \%$ of global sulfur limits would be effective from 2020 instead of 2025 after a postponed 5 years. It meant that regulations in Annex VI of International Convention for the Prevention of Pollution from Ships (MARPOL) which was passed in 2009, made it mandatory for all ships sailing beyond sulfur emissions control area (ECA) to use the fuel with sulfur content less than $0.5 \%$.

Previously, the European Union had agreed to implement a $0.5 \%$ sulfur limit within 200 nautical miles of coastal areas among European Union member states ${ }^{[2,3]}$.

Regulations governing sulfur oxide emissions from ships are included in Annex VI to the International Convention for the prevention of Pollution from ships (MARPOL). Annex VI sets regulations to control emissions from ships, including SOx and NOx. The date of 2020 was agreed in Annex VI amendments adopted in 2008. However, the deadline was a subject to review that had to be completed by 2018 to assess whether sufficient compliant fuel oil would be available to meet the 2020 date. If not, the date could be deferred to 2025. That review, commissioned by the IMO and conducted by CE Delft, was completed in 2016 and submitted to MEPC 70. The review concluded that sufficient compliant fuel oil would be available to meet the fuel oil requirements. 
In its base case scenario, the CE Delft study forecasts that the global demand for marine fuel oil would reach 320 million tonnes in 2020, an 8\% increase from the 2012 demand according to the Motorship (the IMO intends to make the CE Delft report available to the public after MEPC 70). 70\% of this demand would be for fuel oil with $0.1-0.5 \%$ sulfur, and $30 \%$ for oil below $0.1 \%$ sulfur. The study also projects that 3,800 vessels would have scrubbers installed by 2020 , making available around 36 million tonnes of low sulfur fuel due to their continued use of heavy fuel oil. The uptake of alternative fuels, including LNG, was concluded to have an insignificant impact on marine fuel demand by $2020^{[2]}$.

\section{Relevant policies and regulations in China}

In order to implement the relevant international maritime conventions and the law of the People's Republic of China on the prevention and control of air pollution,Pearl river delta, Yangtze river delta, and circum Bohai Sea(Beijing-Tianjin-Hebei Region) area ship discharge control area have been established.Determine the core port area within the emission control zone,the specific implementation and control requirements for the ship's discharge control area have been put forward:Starting from January 1, 2018, the vessel shall use no more than $0.5 \%$ of the fuel in the port of the discharge control area;Since April 1, 2016,Shanghai port has been the first to carry out fuel requirement of no more than $0.5 \%$ of sulphur content in port docked ships.It can be seen from the above indication, that the development of Marine fuel oil in the direction of low sulphur fuel oil will be a significant trend ${ }^{[4]}$.

\section{Analysis of the main countermeasures}

At least three schemes can meet the requirements of the international maritime organization (IMO) : one is to use low sulphur fuel oil, the second is to install sulfide scrubber on board, and the third is to use liquefied natural gas.Each method has its own disadvantages and its adaptability.Now the advantages and disadvantages of these three methods are analyzed, and owners can choose according to their own characteristics ${ }^{[5]}$.

Use 0.5\% low sulphur heavy fuel oil.Undoubtedly If the ship can use $0.5 \%$ low sulfur heavy fuel directly, will be the most ideal solution.But because of demand and cost, there are very few refineries in the world that can produce heavy fuel oil of less than $0.5 \%$ sulfur currently,And the price of this oil is much higher than normal heavy oil (HFO).According to the world's main port Marine fuel quotation on January $17,2018,(0.5 \%$ low sulfur oil has not been widely used, no quotation) $0.1 \%$ low sulfur oil is about $\$ 190 /$ t higher than ordinary heavy oil,It would increase fuel costs significantly.

At present, the difference between $0.1 \%$ low sulfur light oil (MGO) and cSt380 heavy oil in price in world's main ports is about $22-250 \mathrm{usd} /$ ton, the difference between $0.1 \%$ low sulfur heavy fuel and cSt380 heavy oil is around 180-200 usd/ ton.If large quantities of centralized purchasing, the price is expected to fall by 30-40 dollars. Table 1 is the quotation of the world's main port Marine fuel on January 17, 2018. 
Table 1.The world's main port Marine fuel quotation on January 17, 2018 (usd/ton)

\begin{tabular}{|c|c|c|c|c|}
\hline $\begin{array}{c}\text { port } \\
\text { oil }\end{array}$ & $380 \mathrm{cSt}$ & $180 \mathrm{cSt}$ & $0.1 \% \mathrm{MGO}$ & $0.1 \%$ HFO \\
\hline Singapore & 387.5 & 391.5 & 608.5 & 575.5 \\
\hline Rotterdam & 360 & 388 & 593 & 564 \\
\hline Shanghai & 405.5 & 425.5 & 425.5 & No \\
\hline Busan & 417.5 & 437.5 & 636 & No \\
\hline New York & 407 & 437 & 666 & 592 \\
\hline Houston & 385 & 453 & 640 & 575.5 \\
\hline Los Angeles & 404.5 & 443.5 & 639.5 & No \\
\hline Hamburg & 371 & 396 & 610 & No \\
\hline
\end{tabular}

SOx Scrubbers.The advantage of SOx scrubber is that ships can continue to use the common heavy oil (HFO) which is much cheaper than low-sulphur oil,greatly save fuel expense.But the main disadvantage is that both new ships and existing ships need to be added or upgraded with equipment and systems, that adds millions of dollars to each ship and the future operation and maintenance, alkali liquor, management and the waste liquid recovery disposal costs and troubles. There is also a need to increase the power consumption of hundreds to hundreds of kilowatts, taking up space, and there is a risk that the area will be limited and the malfunction will not run properly.According to the group owns a fleet of 850 ships,,single ship investment of $\$ 350$ to $\$ 4$ million, to be spent almost $\$ 3$ billion to $\$ 4$ billion to increase SOx Scrubbers, and to be completed by 2020 , will bring huge capital of pressure and sail schedule lost(Estimated 10-15 days for single ship rehabilitation cycle).In addition, it is also a huge challenge for the shipyard to complete the installation by 2020, which is a difficult task.

what's more, even though the world's $0.5 \%$ low sulphur fuel standard in 2020 doesn't limit the level of PM emissions in clean exhaust,but in MARPOL annex VI article 14, the PM level of exhaust emissions from the scrubber system should be close to the level of low sulphur oil.Although the scrubber can reduce the PM to a certain extent, it is not certain that all scrubber systems can achieve the same level as the use of low sulfur oil.If some cases of scrubber as "equivalent way that could satisfy the requirement of rules" audit withdrawn due to PM to reduce value, or set a PM limit, scrubber may no longer be a meet MARPOL annex VI article 14 of the feasible solution.

LNG fuel.In the long run, LNG is the ideal choice for meeting the new standards of IMO.Because the main components of LNG are methane, compared with fossil fuels, its carbon content is $13 \%$ to $15 \%$, and $\mathrm{CO} 2$ emissions are $25 \%$ to $30 \%$ lower. There is almost no $\mathrm{SO}_{\mathrm{X}}$ and $\mathrm{PM}$ in the burners, and NOX emissions are relatively low ${ }^{[6]}$.

But the use of LNG fuel is faced with many problems.First of all, LNG shipment is inherently dangerous.LNG is a dangerous chemical, but there are no relevant safety regulations for ship equipped with LNG fuel in China.The maintenance and construction of ships shall strictly comply with the corresponding requirements of international gas regulations, and it is also necessary to use strict training crew to reduce the risk factor of fire or explosion. Second, the LNG fuel tank needs more space.The density of LNG is less than half of HFO, and the calorific value is lower than heavy oil. Therefore, the capacity of LNG fuel tank is much larger than fuel oil.This will result in the reduction of ship carrying capacity and economic benefit.Thirdly, the higher cost of maintenance and construction on LNG ship.Gas engine fuel system are more expensive than ordinary engine fuel system. And as a cryogenic liquid, the LNG has to take special precautions to avoid contact with 
people and hull structures. Only special materials, such as stainless steel, aluminum and invar, can be exposed to LNG. When it is in the gas form, the gas has to run in the pipes of the double wall, and the circular space between the walls needs to be inert or ventilated, and to monitor for leaks. This will also increase the cost of building ships.

\section{Opinions and Suggestions.}

Shipowner.First of all,for most existing ships, adding a sulfide scrubber is the best economic option. However, it still needs to pay attention to the operation and maintenance, alkali liquor, management and the recycling and disposal of waste liquid.But we still need a plan to deal with the areas that do not accept the sulfide scrubber.

Second, LNG is the most promising green energy. But,due to its low calorific value and low density(compared with the heavy oil), it is not the best choice for ocean-going vessels. LNG is a good option for luxury cruise ships, ferry boats, and short course ships.

In addition, if the production of $0.5 \%$ of low sulphur fuel oil is sufficient, then the immediate use of $0.5 \%$ low sulphur fuel oil will undoubtedly be the best solution fulfilling the IMO standard.

While currently using $0.5 \%$ of low sulfur fuel oil is much more expensive than high sulfur fuels, with the implementation of the 0.5 per cent sulfur fuel standard in the world 2020, the demand for low sulphur fuel oil for ships will increase, its price is expected to fall $\$ 30$ to $\$ 40$ (compared with high sulphur fuel). Therefore, no matter from the simplified management, reduce troubles and avoid risk, responsibility, bear and improve their image and save operational costs, avoid time lost, or in the future, sweet oil and general heavy oil price will gradually narrow Angle comprehensive analysis and comparison,the use of $0.5 \%$ low sulfur fuel oil scheme is the most suitable and in line with the development trend of low sulfur in marine fuel oil.

Refinery enterprise.In less than three years, global Marine fuel oil needs to reduce its sulphur content from $3.5 \%$ to $0.5 \%$. The decision is bound to have a huge impact on refineries, traders and shipowners worldwide, including China, and perhaps the Marine fuel oil market will change radically.If Chinese refineries can produce enough low sulphur fuel oil,it is expected to reduce the price of low sulphur fuel oil in china, which will play an active role in enhancing the international market competitiveness of China's Marine low sulfur fuel oil.

\section{Acknowledgements}

This study was supported by the Demonstration Project of Marine Economic Innovation and Development of Zhoushan City of China.

\section{References}

[1] Guangyuan Liang:Neglected Pollution Sources,Environment,2016(06)

[2] Information on https://www.dieselnet.com/news/2016/10imo.php.

[3] Jinhao Fu:Ship Fuel Management in The Sulfur Control Area,China Ship Survey,2016

[4] Xiaomin xiang and Huali Long:Interpretation of Marine Fuel Oil Standard,Petroleum Products Application Research,2016(03)

[5] Wanxia Li and Banglong Nie:The Latest Requirements and Response Analysis of Ship Sulfur Emission Limits,Technological Development of Enterprise,2014(15)

[6] Yuan Li:The Ship Meets the Choice of Sulfur Emission Limit Scheme,Marine Equipment/Materials \& Marketing.2016 